\title{
Uretero-Inguinal Herniation: A Rare Complication of Ureteral Duplication
}

\author{
Abigail Hayward ${ }^{\mathrm{a}, \mathrm{b}}$, Rafid Al-sam ${ }^{\mathrm{c}}$, Grenville Oades ${ }^{\mathrm{a}}$, \\ Michael Fraser ${ }^{\mathrm{c}}$, Prabhakar Rajan ${ }^{\mathrm{a}, \mathrm{d}, \mathrm{e}}$
}

\begin{abstract}
We report an unusual case of an 83-year old male with incidental left uretero-inguinal herniation of one of two partially-duplicated ureters. Partial or complete ureteral duplication is the most common developmental urinary tract anomaly. Although ureters may be involved in inguino-scrotal herniae, however involvement of duplicated ureter(s) is extremely rare.
\end{abstract}

Keywords: Ureteral duplication; Duplex ureter; Retro-peritoneal hernia; Para-peritoneal hernia

\section{Case Report}

An 83-year old male with benign prostatic enlargement (BPE) presented with acute urinary retention with renal failure, constipation and weight loss. On examination, he had large bilateral asymptomatic inguinal herniae. Following catheterisation and medical renal failure management, a contrast-enhanced CT scan was performed to investigate his constitutional symptoms. An incidental finding was partial left ureteral duplication, and urography revealed that the distal part of one limb looped into the left inguinal hernia before inserting into the bladder (Fig. 1-4). The patient's renal function normalised with catheterisation, which was definitive

Manuscript accepted for publication June 11, 2012

\footnotetext{
${ }^{a}$ Departments of Urology, Southern General Hospital, Glasgow, UK ${ }^{\mathrm{b}}$ Emergency Department, Forth Valley Royal Hospital, Larbet, FK5 4WR, UK

${ }^{\mathrm{c}}$ Departments of Radiology, Southern General Hospital, Glasgow, UK ${ }^{\mathrm{d}}$ Department of Urology, Monklands Hospital, Airdrie, ML6 0JS, UK ${ }^{\mathrm{e}}$ Corresponding author: Prabhakar Rajan, Beatson Institute for Cancer Research, Garscube Estate, Switchback Road, Bearsden, G61 1BD, UK. Email: p.rajan@beatson.gla.ac.uk
}

doi:10.4021/wjnu26w management of his BPE due to medical co-morbidities.

\section{Discussion}

Ureteral duplication is the commonest developmental anomaly of the urinary tract, usually asymptomatic and an incidental radiological finding. Incomplete duplication is three times more common than complete duplication (about 1:500 births). Embrologically, incomplete duplication is thought to be due to premature bifurcation of the ureteral bud prior to insertion into the metanephric blastema. Ureteric convergence typically occurs in the distal third of the ureteric course with a common intravesical ureteric orifice. Complete duplication occurs when the metanephric duct sprouts two ureteric buds, which penetrate the metanephric blastema independently. The ureter originating from the lower pole inserts into the bladder in its normal position, whereas the ureter from the upper pole crosses the orthotopic ureter and inserts ectopically infero-medially (Weigert-Meyer rule) into any mesonephric duct-derived structure. In females, the ectopic ureter usually opens below the level of the urinary sphincter causing incontinence, however a supra-sphincteric

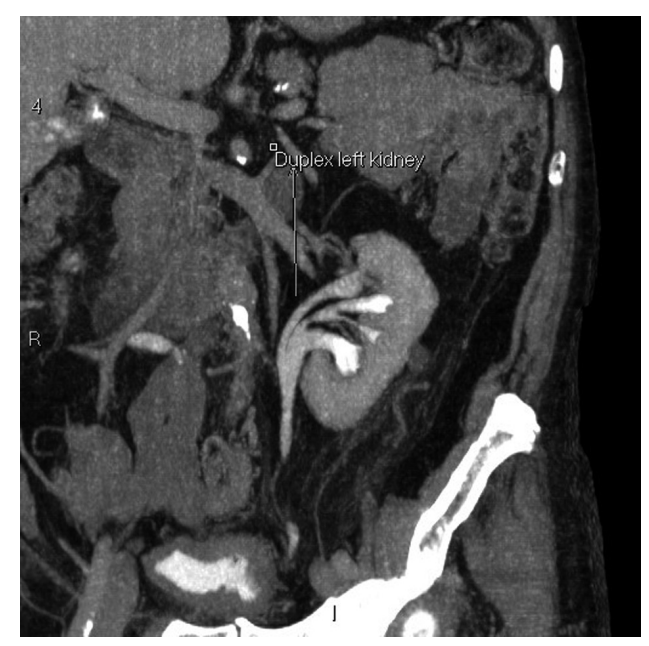

Figure 1. Coronal reconstruction of abdominal and pelvic CT urogram demonstrating duplex left kidney. 


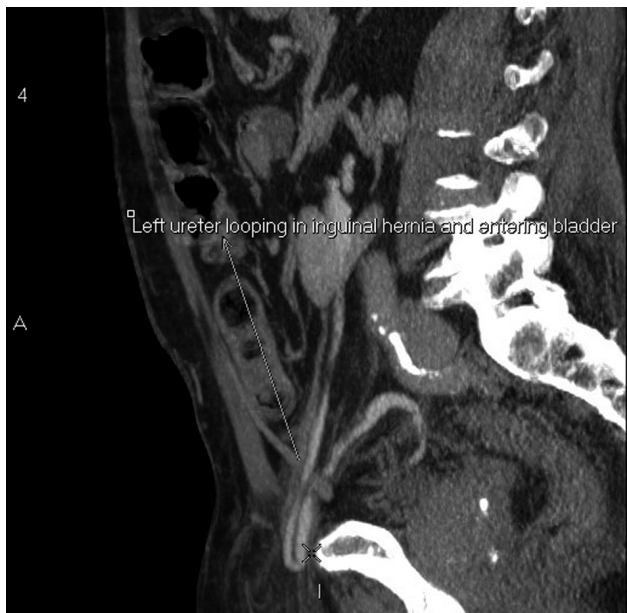

Figure 2. Sagittal reconstruction of abdominal and pelvic CT urogram demonstrating one limb of the partially-duplicated left ureter entering and leaving the inguinal canal.

insertion in males preserves continence.

Inguino-scrotal herniation of the urinary bladder within a "sliding hernia" (in which the organ involved forms part of the wall of the hernia sac) is not uncommon, however ureteric involvement (native or transplanted) is rare [1,2]. Eighty per cent are paraperitoneal, where the hernia has peritoneum antero-medially in addition to the ureter (and other organs) adherent to the postero-lateral peritoneum as part of the sac [3]. Due to their large size and reducibility, patients are usually asymptomatic, except where ureteric obstruction causes pain and hydronephrosis [4] and bladder involvement causes LUTS. Paraperitoneal herniae are very infrequently associated with other renal tract anomalies. Extraperitoneal herniae have no sac, contain fat and ureter only, and are thought to arise from failure of ureteric differentiation from the meso-

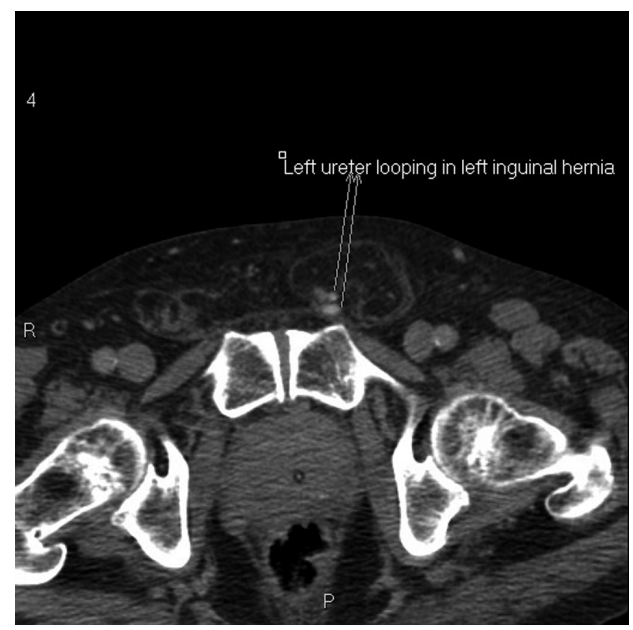

Figure 3. Axial pelvic CT urogram demonstrating afferent and efferent part of the ureteric limb within the inguinal canal.

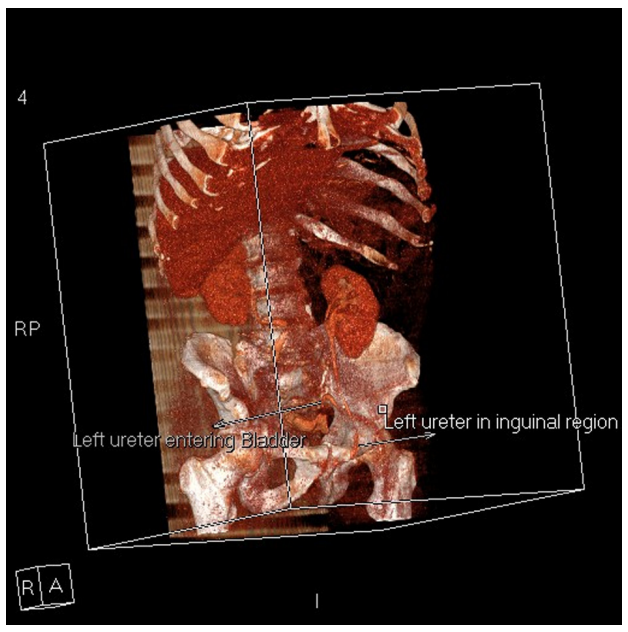

Figure 4. 3-D reconstruction of abdominal and pelvic CT urogram demonstrating one limb of the partially-duplicated left ureter entering and leaving the inguinal canal before entering the bladder.

nephric duct. Adhesions between the developing ureter and genital ligaments can pull the ureter down into a hernia. Extraperitoneal ureteral herniae are frequently associated with other congenital urinary tract anomalies (about 50\% cases). These small herniae tend to be irreducible but usually do not cause symptoms of urinary tract obstruction. To the best of our knowledge, there is only one previously-published report of inguino-scrotal herniation of duplicated ureters, which involved both limbs [3]

\section{Conclusion}

Although inguinal herniation of a duplicated ureter was incidental finding in the above case, we highlight a rare but important anatomical variant affecting common inguino-scrotal pathology. To avoid damage to this vital structure, significant peri-operative care should be taken when undertaking inguinal hernia surgery. Although most cases will be incidental findings, consideration to the differential diagnosis should be given in patients with inguinal herniae and evidence of ureteric obstruction.

\section{Conflict of Interest}

None declared.

\section{References}

1. Odisho AY, Freise CE, Tomlanovich SJ, Vagefi PA. Inguinal herniation of a transplant ureter. Kidney Int. 2010;78(1):115. 
2. Sripathi S, Rajagopal K, Kakkar C, Polnaya A. Case Report-Inguinoscrotal ureteral hernia diagnosed on micturating cystourethrography. Indian J Radiol Imaging. 2011;21(3):199-201.

3. Bertolaccini L, Giacomelli G, Bozzo RE, Gastaldi $\mathrm{L}$, Moroni M. Inguino-scrotal hernia of a double dis- trict ureter: case report and literature review. Hernia. 2005;9(3):291-293.

4. Massoud W, Eschwege P, Hajj P, Awad A, Iaaza LA, Chabenne J, Hammoudi Y, et al. Hydronephrosis secondary to sliding inguinal hernia containing the ureter. Urol J. 2011;8(4):333-334. 